\title{
A thermodynamic potential for barium zirconate titanate solid solutions
}

\author{
Jinlin Peng ${ }^{1}$, Dongliang Shan ${ }^{1}$, Yunya Liu ${ }^{1}$, Kai Pan ${ }^{1}$, Chihou Lei ${ }^{2}$, Ningbo He ${ }^{1}$, Zhenyu Zhang ${ }^{1}$ and Qiong Yang ${ }^{1}$
}

Barium zirconate titanate $\left[\mathrm{Ba}\left(\mathrm{Zr}_{x} \mathrm{Ti}_{1-x}\right) \mathrm{O}_{3}\right]$ solid solutions are promising lead-free ferroelectric materials that have received substantial interest. Thermodynamic analysis based on phenomenological Landau-Devonshire theory is a powerful method for theoretical investigation of ferroelectric materials, but cannot be applied to $\mathrm{Ba}\left(\mathrm{Zr}_{x} \mathrm{Ti}_{1-x}\right) \mathrm{O}_{3}$ because there is no thermodynamic potential. In this paper, a thermodynamic potential for $\mathrm{Ba}\left(\mathrm{Zr}_{x} \mathrm{Ti}_{1-x}\right) \mathrm{O}_{3}(0 \leq x \leq 0.3)$ solid solutions is constructed, and then a thermodynamic analysis carried out. The results accurately reproduce known phase structures and their transition temperatures, with good agreement with experimentally measured polarization, dielectric, and piezoelectric constants. It is found that $\mathrm{Ba}\left(\mathrm{Zr}_{x} \mathrm{Ti}_{1-x}\right)$ $\mathrm{O}_{3}$ solid solutions at room temperature have three phase boundaries, including a tetragonal-orthorhombic phase boundary at $x=$ 0.013 , an orthorhombic-rhombohedral phase boundary at $x=0.0798$, and a rhombohedral-paraelectric phase boundary at $x=$ 0.2135. The results also indicate that the chemical composition-induced ferroelectric-paraelectric phase boundary has superior electromechanical properties, suggesting a new way to enhance electromechanical coupling in $\mathrm{Ba}\left(\mathrm{Zr}_{x} \mathrm{Ti}_{1-x}\right) \mathrm{O}_{3}$ solid solutions.

npj Computational Materials (2018)4:66 ; doi:10.1038/s41524-018-0126-3

\section{INTRODUCTION}

Ferroelectrics with switchable polarization, excellent dielectric, piezoelectric, and pyroelectric properties have a wide range of applications in memories, capacitors, actuators, sensors, and electrocaloric cooling devices. ${ }^{1-12}$ As a typical ferroelectric material, barium titanate $\left(\mathrm{BaTiO}_{3}\right)$ possesses a rich variety of phase transitions. ${ }^{13}$ Above its Curie temperature $\left(T_{C} \sim 120^{\circ} \mathrm{C}\right)$, the $\mathrm{BaTiO}_{3}$ single crystal is paraelectric phase with cubic symmetry. ${ }^{13}$ When the $\mathrm{BaTiO}_{3}$ single crystal is cooled through Curie temperature, it undergoes a paraelectric to ferroelectric phase transition, and has a tetragonal phase structure with polarization along $\langle 100\rangle$ direction. ${ }^{13}$ When the cooling is continued, the $\mathrm{BaTiO}_{3}$ single crystal exhibits a tetragonal ferroelectric to orthorhombic ferroelectric phase transition at about $T_{\mathrm{T} \leftrightarrow \mathrm{O}} \sim 0{ }^{\circ} \mathrm{C}$ with polarization along $\langle 110\rangle$ direction. ${ }^{13}$ Upon further cooling, the $\mathrm{BaTiO}_{3}$ single crystal shows an orthorhombic ferroelectric to rhombohedral ferroelectric phase transition around $T_{\mathrm{O} \leftrightarrow \mathrm{R}} \sim-80^{\circ} \mathrm{C}$ with polarization along $<111>$ direction. ${ }^{13}$ Thus, $\mathrm{BaTiO}_{3}$ has three types of phase transitions, including one ferroelectric-paraelectric (FE-PE) phase transition and two ferroelectric-ferroelectric (FE-FE) phase transitions. The corresponding phase transition temperatures can be tuned by the substitution of $\mathrm{Ti}^{4+}$ with $\mathrm{Zr}^{4+},{ }^{14,15}$ which forms barium zirconate titanate $\left[\mathrm{Ba}\left(\mathrm{Zr}_{x} \mathrm{Ti}_{1-x}\right) \mathrm{O}_{3}\right]$ solid solutions. In $\mathrm{Ba}\left(\mathrm{Zr}_{x} \mathrm{Ti}_{1-\chi}\right) \mathrm{O}_{3}$ system, the FE-FE phase transition temperatures $T_{\mathrm{T} \leftrightarrow \mathrm{O}}$ and $T_{\mathrm{O} \leftrightarrow \mathrm{R}}$ increase with the increase in composition of $\mathrm{Zr}$, whereas the FE-PE phase transition temperature $T_{C}$ decreases with increasing composition $x$, and all three phase transitions are pinched into a single phase transition around $x=0.15{ }^{15,16}$ suggesting a pinched phase transition feature. With further increase in composition $x, \mathrm{Ba}\left(\mathrm{Zr}_{x} \mathrm{Ti}_{1-x}\right) \mathrm{O}_{3}$ solid solutions only have FE-PE phase transitions between rhombohedral and cubic phase structures, and the corresponding phase transition temperature $T_{\mathrm{C}}$ decreases. $^{15}$

$\mathrm{Ba}\left(\mathrm{Zr}_{x} \mathrm{Ti}_{1-x}\right) \mathrm{O}_{3}$ solid solutions have been studied widely on the experimental aspects. For example, the phase structures of $\mathrm{Ba}$ $\left(\mathrm{Zr}_{x} \mathrm{Ti}_{1-x}\right) \mathrm{O}_{3}$ solid solutions at different temperatures were investigated by $\mathrm{Yu}^{16,17}$ et al., and the phase transition temperatures were identified for the low-composition range $(x=0,0.05$, $0.08,0.1,0.15,0.2,0.25,0.3),{ }^{13,16-22}$ revealing that a pinched phase transition occurs near the composition $x=0.15{ }^{15,16}$ Also, previous experimental observations displayed that $\mathrm{Ba}\left(\mathrm{Zr}_{x} \mathrm{Ti}_{1-x}\right) \mathrm{O}_{3}$ with composition $x=0.08$ has a coexistence of orthorhombic and rhombohedral phases at a temperature of $30^{\circ} \mathrm{C}$, and possesses an enhancement of piezoelectric response near this polymorphic phase boundary. ${ }^{22}$ In addition, Yu et al. studied the dielectric properties of $\mathrm{Ba}\left(\mathrm{Zr}_{x} \mathrm{Ti}_{1-x}\right) \mathrm{O}_{3}$ solid solutions, and found that $\mathrm{Ba}$ $\left(\mathrm{Zr}_{x} \mathrm{Ti}_{1-x}\right) \mathrm{O}_{3}$ solid solutions have stronger dielectric response than that of pure $\mathrm{BaTiO}_{3}{ }^{21}$ Recently, Qian et al. discovered that $\mathrm{Ba}$ $\left(\mathrm{Zr}_{x} \mathrm{Ti}_{1-x}\right) \mathrm{O}_{3}$ solid solutions show a giant electrocaloric effect over a broad temperature range. ${ }^{23}$ Thus, the previous experimental results indicate that $\mathrm{Ba}\left(\mathrm{Zr}_{x} \mathrm{Ti}_{1-x}\right) \mathrm{O}_{3}$ solid solutions have great potential applications. However, the phase diagram and electromechanical properties with continuous variation in composition have not been accomplished.

Although the experimental advances in $\mathrm{Ba}\left(\mathrm{Zr}_{x} \mathrm{Ti}_{1-x}\right) \mathrm{O}_{3}$ solid solutions are encouraging, the corresponding theoretical studies are rare. Thermodynamic analysis based on phenomenological Landau-Devonshire theory is a powerful method for the theoretical investigation of ferroelectric materials. ${ }^{3,7,24-35}$ In order to implement thermodynamic analysis, the thermodynamic potential of a particular ferroelectric system should be established first. Haun et al. have established the thermodynamic potential for lead zirconate titanate (PZT) solid solution based on its phase

\footnotetext{
${ }^{1}$ Key Laboratory of Low Dimensional Materials and Application Technology of Ministry of Education, School of Materials Science and Engineering, Xiangtan University, Hunan 411105, China and ${ }^{2}$ Department of Aerospace and Mechanical Engineering, Saint Louis University, Saint Louis, MO 63103, USA Correspondence: Yunya Liu (yyliu@xtu.edu.cn)
}

Received: 30 March 2018 Accepted: 13 November 2018

Published online: 30 November 2018 
structures and electromechanical properties in single crystals and bulk ceramics. ${ }^{36}$ Similarly, Bell and Cross $^{37}$ constructed a sixthorder thermodynamic potential for $\mathrm{BaTiO}_{3}$, which was revised as an eighth-order thermodynamic potential by Li et al. ${ }^{26}$ After that, Wang et al. $^{38}$ reported another eighth-order thermodynamic potential, in which the second and higher-order coefficients are dependent on temperature. In order to consider the quantum mechanical effects at low temperature, Wang et al. ${ }^{39}$ proposed a modified thermodynamic potential for $\mathrm{BaTiO}_{3}$, based on which the calculated phase transitions in temperature-pressure phase diagram show excellent agreement with experimental data. With the established thermodynamic potentials, the thermodynamic analysis on PZT solid solution and $\mathrm{BaTiO}_{3}$ have been implemented widely for explaining and predicting new physical phenomena. ${ }^{40-}$ 42 On the other hand, the known thermodynamic potential is a necessary condition for simulating ferroelectric domain structures via the conventional phase-field method. ${ }^{43-46}$ Thus, thermodynamic potential plays an important role in the theoretical analysis of ferroelectrics. However, the thermodynamic potential of $\mathrm{Ba}$ $\left(\mathrm{Zr}_{x} \mathrm{Ti}_{1-\chi}\right) \mathrm{O}_{3}$ solid solutions is unestablished and lacking. This is also one reason for rare theoretical studies on $\mathrm{Ba}\left(\mathrm{Zr}_{x} \mathrm{Ti}_{1-x}\right) \mathrm{O}_{3}$ solid solutions. Thus, we seek to construct thermodynamic potential for $\mathrm{Ba}\left(\mathrm{Zr}_{x} \mathrm{Ti}_{1-x}\right) \mathrm{O}_{3}(0 \leq x \leq 0.3)$ solid solutions, and then employ it to study and predict the phase diagram as well as electromechanical properties of $\mathrm{Ba}\left(\mathrm{Zr}_{x} \mathrm{Ti}_{1-x}\right) \mathrm{O}_{3}$ solid solutions via theoretical analysis.

\section{RESULTS AND DISCUSSION}

Constructing thermodynamic potential

Thermodynamic potential is the key factor for the thermodynamic theory of ferroelectrics, which is lacking for $\mathrm{Ba}\left(\mathrm{Zr}_{x} \mathrm{Ti}_{1-x}\right) \mathrm{O}_{3}$ solid solutions. Thus, we seek to construct it for $\mathrm{Ba}\left(\mathrm{Zr}_{x} \mathrm{Ti}_{1-x}\right) \mathrm{O}_{3}$ solid solutions. Based on the phenomenological Landau-Devonshire theory, the thermodynamic potential always uses polarization as an order parameter to describe the phase transitions in ferroelectrics. ${ }^{36}$ With the free energy of paraelectric phase at Curie temperature as a reference, the thermodynamic potential energy of a ferroelectric crystal under isothermal condition can be expanded in powers of polarization $P_{i}(i=1,2,3)$ and stress $\sigma_{I}(I=$ $1,2, \ldots, 6),{ }^{47-49}$

$$
\begin{aligned}
G=a_{1} & \left(P_{1}^{2}+P_{2}^{2}+P_{3}^{2}\right)+a_{11}\left(P_{1}^{4}+P_{2}^{4}+P_{3}^{4}\right)+a_{12}\left(P_{1}^{2} P_{2}^{2}+P_{1}^{2} P_{3}^{2}+P_{2}^{2} P_{3}^{2}\right) \\
& +a_{111}\left(P_{1}^{6}+P_{2}^{6}+P_{3}^{6}\right)+a_{112}\left[P_{1}^{2}\left(P_{2}^{4}+P_{3}^{4}\right)+P_{2}^{2}\left(P_{1}^{4}+P_{3}^{4}\right)+P_{3}^{2}\left(P_{1}^{4}+P_{2}^{4}\right)\right] \\
& +a_{123} P_{1}^{2} P_{2}^{2} P_{3}^{2}+a_{1111}\left(P_{1}^{8}+P_{2}^{8}+P_{3}^{8}\right)+a_{1122}\left(P_{1}^{4} P_{2}^{4}+P_{1}^{4} P_{3}^{4}+P_{2}^{4} P_{3}^{4}\right) \\
& +a_{1112}\left[P_{1}^{2}\left(P_{2}^{6}+P_{3}^{6}\right)+P_{2}^{2}\left(P_{1}^{6}+P_{3}^{6}\right)+P_{3}^{2}\left(P_{1}^{6}+P_{2}^{6}\right)\right] \\
& +a_{1123}\left(P_{1}^{2} P_{2}^{2} P_{3}^{4}+P_{1}^{2} P_{2}^{4} P_{3}^{2}+P_{1}^{4} P_{2}^{2} P_{3}^{2}\right) \\
& -\frac{S_{11}}{2}\left(\sigma_{1}^{2}+\sigma_{2}^{2}+\sigma_{3}^{2}\right)-\frac{S_{44}}{2}\left(\sigma_{4}^{2}+\sigma_{5}^{2}+\sigma_{6}^{2}\right)-S_{12}\left(\sigma_{1} \sigma_{2}+\sigma_{2} \sigma_{3}+\sigma_{1} \sigma_{3}\right) \\
& -Q_{11}\left(\sigma_{1} P_{1}^{2}+\sigma_{2} P_{2}^{2}+\sigma_{3} P_{3}^{2}\right)-Q_{12}\left[\sigma_{3}\left(P_{1}^{2}+P_{2}^{2}\right)+\sigma_{2}\left(P_{1}^{2}+P_{3}^{2}\right)+\sigma_{1}\left(P_{2}^{2}+P_{3}^{2}\right)\right] \\
& -Q_{44}\left(\sigma_{6} P_{1} P_{2}+\sigma_{4} P_{2} P_{3}+\sigma_{5} P_{1} P_{3}\right)-P_{1} E_{1}-P_{2} E_{2}-P_{3} E_{3},
\end{aligned}
$$

in which $E_{i}$ is the electric field, $Q_{I J}, S_{I J}$ are the electrostrictive coefficient and elastic compliance constant under constant polarization in Voigt notation, respectively. It should be noted that $a_{1}, a_{i j}, a_{i j k}$ and $a_{i j k l}$ are the thermodynamic potential coefficients, all of which are unknown for $\mathrm{Ba}\left(\mathrm{Zr}_{x} \mathrm{Ti}_{1-x}\right) \mathrm{O}_{3}$ solid solutions. Estimating the values of these coefficients can then construct the thermodynamic potential of $\mathrm{Ba}\left(\mathrm{Zr}_{x} \mathrm{Ti}_{1-x}\right) \mathrm{O}_{3}$ solid solutions.

According to the thermodynamic theory, phase structures and electromechanical properties of ferroelectrics can be calculated using thermodynamic analysis from thermodynamic potential. ${ }^{36,49}$ The polarization of ferroelectrics can be determined by minimizing thermodynamic potential, that is, by solving the derivatives of thermodynamic potential with respect to polarization compo-

\begin{tabular}{|c|c|c|c|c|c|c|c|c|}
\hline Coefficient & $\overline{0^{\mathrm{a}}}$ & 0.05 & $0.08^{\mathrm{b}}$ & 0.1 & 0.15 & 0.2 & 0.25 & 0.3 \\
\hline$T_{0}\left({ }^{\circ} \mathrm{C}\right)$ & 115 & 107 & 100 & 84 & 64 & 32 & -10 & -52 \\
\hline$a_{1}{ }^{*} \mathrm{c}\left[10^{5} \mathrm{~m}^{2} \mathrm{~N} /\left(\mathrm{C}^{2} \cdot{ }^{\circ} \mathrm{C}\right)\right]$ & 4.124 & 4.6 & 4.45 & 3.53 & 3.45 & 3.12 & 1.9 & 1.6 \\
\hline$a_{11}\left(10^{8} \mathrm{~m}^{6} \mathrm{~N} / \mathrm{C}^{4}\right)$ & -2.097 & -1.98 & -1.964 & -1.5 & -4.66 & -15.1 & -17.2 & -19.2 \\
\hline$a_{112}\left(10^{9} \mathrm{~m}^{10} \mathrm{~N} / \mathrm{C}^{6}\right)$ & -1.95 & -9.85 & -19.42 & -18.5 & -13.28 & -5.28 & -2.88 & -2.38 \\
\hline$a_{123}\left(10^{9} \mathrm{~m}^{10} \mathrm{~N} / \mathrm{C}^{6}\right)$ & -2.5 & -5.72 & -2.132 & -1.8 & -1.2 & -0.75 & -0.35 & -0.15 \\
\hline$a_{1111}\left(10^{10} \mathrm{~m}^{14} \mathrm{~N} / \mathrm{C}^{8}\right)$ & 3.863 & 9.65 & 15.08 & 14.3 & 9.1 & 0 & 0 & 0 \\
\hline$a_{1112}\left(10^{10} \mathrm{~m}^{14} \mathrm{~N} / \mathrm{C}^{8}\right)$ & 2.529 & 4.421 & 6.333 & 9.4 & 12.5 & 0 & 0 & 0 \\
\hline$a_{1122}\left(10^{10} \mathrm{~m}^{14} \mathrm{~N} / \mathrm{C}^{8}\right)$ & 1.637 & 4.821 & 8.005 & 10.5 & 12.6 & 0 & 0 & 0 \\
\hline$S_{44}\left(10^{-12} \mathrm{~m}^{2} / \mathrm{N}\right)$ & \multicolumn{8}{|c|}{$9.24+5.05 x$} \\
\hline$Q_{11}\left(\mathrm{~m}^{4} / \mathrm{C}^{2}\right)$ & \multicolumn{8}{|c|}{$0.1-0.004 x$} \\
\hline$Q_{12}\left(\mathrm{~m}^{4} / \mathrm{C}^{2}\right)$ & \multicolumn{8}{|c|}{$-0.034-0.005 x$} \\
\hline$Q_{44}\left(m^{4} / C^{2}\right)$ & \multicolumn{8}{|c|}{$0.029+0.002 x$} \\
\hline
\end{tabular}
nents for zeros,

$\frac{\partial G}{\partial P_{1}}=0, \frac{\partial G}{\partial P_{2}}=0, \frac{\partial G}{\partial P_{3}}=0$.

The phase structures are classified by the solutions of the equilibrium polarization states, which include four sets of solutions corresponding to four different phase structures: (i) the paraelectric (PE) phase with $P_{1}=P_{2}=P_{3}=0$; (ii) the tetragonal (T) phase with $P_{1}$ 
$=P_{2}=0, P_{3} \neq 0$ (or $P_{1}=P_{3}=0, P_{2} \neq 0 ; P_{2}=P_{3}=0, P_{1} \neq 0$ ), (iii) the orthorhombic (O) phase with $P_{1}=0,\left|P_{2}\right|=\left|P_{3}\right| \neq 0$ (or $P_{2}=0,\left|P_{1}\right|=\mid$ $P_{3}\left|\neq 0 ; P_{3}=0,\right| P_{1}|=| P_{2} \mid \neq 0$ ); and (iv) the rhombohedral (R) phase with $\left|P_{1}\right|=\left|P_{2}\right|=\left|P_{3}\right| \neq 0$. With the determination of polarization, the relative dielectric constants can be evaluated by

$\varepsilon_{i j}=1+\frac{\eta_{i j}}{\varepsilon_{0}}$

with $\varepsilon_{0}$ being the permittivity of free space and

$\eta=\left(\begin{array}{lll}\frac{\partial^{2} G}{\partial P_{1} \partial P_{1}} & \frac{\partial^{2} G}{\partial P_{1} \partial P_{2}} & \frac{\partial^{2} G}{\partial P_{1} \partial P_{3}} \\ \frac{\partial^{2} G}{\partial P_{2} \partial P_{1}} & \frac{\partial^{2} G}{\partial P_{2} \partial P_{2}} & \frac{\partial^{2} G}{\partial P_{2} \partial P_{3}} \\ \frac{\partial^{2} G}{\partial P_{3} \partial P_{1}} & \frac{\partial^{2} G}{\partial P_{3} \partial P_{2}} & \frac{\partial^{2} G}{\partial P_{3} \partial P_{3}}\end{array}\right)^{-1}$.

The piezoelectric coefficients $d_{i n}(n=1,2, \ldots, 6)$

$d_{i n}=\frac{\partial \varepsilon_{n}}{\partial E_{i}}=\frac{\partial \varepsilon_{n}}{\partial P_{1}} \eta_{i 1}+\frac{\partial \varepsilon_{n}}{\partial P_{2}} \eta_{i 2}+\frac{\partial \varepsilon_{n}}{\partial P_{3}} \eta_{i 3}$,

where the strain $\varepsilon_{n}$ can be obtained by the relationship

$\varepsilon_{n}=-\frac{\partial G}{\partial \sigma_{n}}$.

The above derivation of thermodynamic analysis reveals that phase structures and electromechanical properties of ferroelectrics are correlated with thermodynamic potential directly. As such, the inverse determination of thermodynamic potential coefficients of $\mathrm{Ba}\left(\mathrm{Zr}_{x} \mathrm{Ti}_{1-x}\right) \mathrm{O}_{3}$ solid solutions can be estimated via fitting the available experimental data of phase structures, phase transition temperatures, polarization, and dielectric constants reported in literatures. ${ }^{13,16-22,26,50-57}$ The experimental data used for fitting are listed in Supplementary Table S1. The details of determining thermodynamic potential coefficients for $\mathrm{Ba}\left(\mathrm{Zr}_{x} \mathrm{Ti}_{1-x}\right)$ $\mathrm{O}_{3}$ solid solutions are given in section METHODS and schematically illustrated in Supplementary Fig. S1. A similar procedure has been applied successfully to construct the thermodynamic potentials for $\left(\mathrm{K}_{1-x} \mathrm{Na}_{x}\right) \mathrm{NbO}_{3}$ and $\left(\mathrm{Ba}_{1-x} \mathrm{Sr}_{x}\right) \mathrm{TiO}_{3}{ }^{58,59}$ The determined thermodynamic potential coefficients of $\mathrm{Ba}\left(\mathrm{Zr}_{x} \mathrm{Ti}_{1-x}\right) \mathrm{O}_{3}$ solid solutions are tabulated in Table 1.
It is noticed that electromechanical coupling terms are also included in the thermodynamic potential energy [Eq. (1)], and can be determined if elastic compliance constant $S_{I J}$ and electrostrictive coefficient $Q_{I J}$ are known. Since the elastic compliance constants and electrostrictive coefficients data of $\mathrm{Ba}\left(\mathrm{Zr}_{x} \mathrm{Ti}_{1-x}\right) \mathrm{O}_{3}$ are unavailable in literature, both of them are evaluated from a linear interpolation of the corresponding data of $\mathrm{BaTiO}_{3}$ and $\mathrm{BaZrO}_{3}$, given by $S_{I J}=(1-x) S_{I J}^{\mathrm{BaTiO}_{3}}+x S_{I J}^{\mathrm{BaZrO}_{3}}$ and $Q_{I J}=(1-x) Q_{I J}^{\mathrm{BaTiO}_{3}}+x Q_{I J}^{\mathrm{BaZrO}_{3}}$. A similar method was adopted by Huang et al. to obtain the electrostrictive coefficients of $\left(\mathrm{Ba}_{1}\right.$ $\left.{ }_{-x} \mathrm{Sr}_{x}\right) \mathrm{TiO}_{3}{ }^{59}$ Notice that $S_{11}^{\mathrm{BaTiO}_{3}}=8.3 \times 10^{-12} \mathrm{~m}^{2} / \mathrm{N}, \quad S_{12}^{\mathrm{BaTiO}_{3}}=$ $-2.7 \times 10^{-12} \mathrm{~m}^{2} / \mathrm{N}, \quad S_{44}^{\mathrm{BaTiO}_{3}}=9.24 \times 10^{-12} \mathrm{~m}^{2} / \mathrm{N}, \quad S_{11}^{\mathrm{BaZrO}_{3}}=3.43 \times$ $10^{-12} \mathrm{~m}^{2} / \mathrm{N}, \quad S_{12}^{\mathrm{BaZrO}_{3}}=-0.675 \times 10^{-12} \mathrm{~m}^{2} / \mathrm{N}, \quad S_{44}^{\mathrm{BaZrO}}=14.29$ $\times 10^{-12} \mathrm{~m}^{2} / \mathrm{N}, \quad Q_{11}^{\mathrm{BaTiO}_{3}}=0.1 \mathrm{~m}^{4} / \mathrm{C}^{2}, Q_{12}^{\mathrm{BaTiO}_{3}}=-0.034 \mathrm{~m}^{4} / \mathrm{C}^{2}$, and $Q_{44}^{\mathrm{BaTiO}_{3}}=0.029 \mathrm{~m}^{4} / \mathrm{C}^{2} \cdot{ }^{29,60,61}$ Due to the lack of available data, we adopt the similar method described by Wang et al., ${ }^{62}$ and obtain the electrostrictive coefficients of $\mathrm{BaZrO}_{3}\left(Q_{11}^{\mathrm{BaZrO}_{3}}=0.096 \mathrm{~m}^{4} / \mathrm{C}^{2}\right.$, $Q_{12}^{\mathrm{BaZrO}_{3}}=-0.039 \mathrm{~m}^{4} / \mathrm{C}^{2}$, and $\left.Q_{44}^{\mathrm{BaZrO}_{3}}=0.031 \mathrm{~m}^{4} / \mathrm{C}^{2}\right)$ using combined first-principles calculations and Berry's phase approach (details in the Supporting Information). Since experimental data of electrostrictive coefficients of $\mathrm{BaZrO}_{3}$ are not available, we compare the hydrostatic electrostrictive coefficient $Q_{h}=Q_{11}+$ $2 Q_{12}$ between the calculation and experiment, and good agreement is observed, as details in the Supporting Information. As such, the thermodynamic potential of $\mathrm{Ba}\left(\mathrm{Zr}_{x} \mathrm{Ti}_{1-x}\right) \mathrm{O}_{3}$ solid solutions has been constructed, as tabulated in Table 1. The known thermodynamic potential allows us to carry out thermodynamic analysis for $\mathrm{Ba}\left(\mathrm{Zr}_{x} \mathrm{Ti}_{1-x}\right) \mathrm{O}_{3}$ solid solutions, and also makes it possible to realize phase-field simulations for $\mathrm{Ba}\left(\mathrm{Zr}_{x} \mathrm{Ti}_{1-x}\right) \mathrm{O}_{3}$ solid solutions. At low temperature, phase transitions and electromechanical properties of ferroelectrics are significantly affected by low-temperature quantum mechanical effects, ${ }^{39,63}$ which is not considered in this work, due to the lack of corresponding lowtemperature experimental data of $\mathrm{Ba}\left(\mathrm{Zr}_{x} \mathrm{Ti}_{1-\chi}\right) \mathrm{O}_{3}$ solid solutions for fitting thermodynamic potential coefficients.
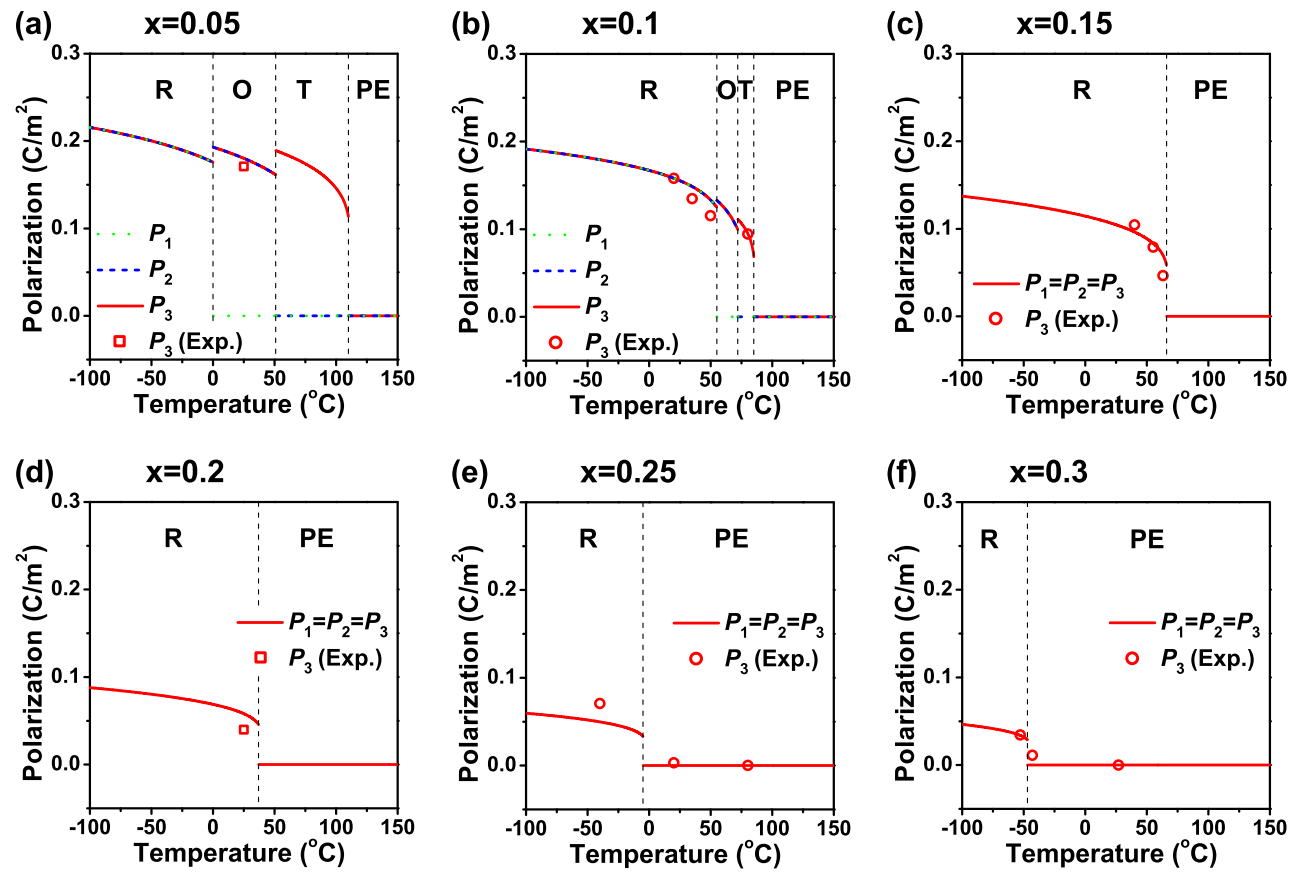

Fig. 1 Polarization of $\mathrm{Ba}\left(\mathrm{Zr}_{x} \mathrm{Ti}_{1-x}\right) \mathrm{O}_{3}$ solid solutions as a function of temperature. $\mathbf{a} x=0.05, \mathbf{b} x=0.1, \mathbf{c} x=0.15, \mathbf{d} x=0.2$, e $x=0.25$, and $\mathbf{f} x=$ 0.3 , the experimental data of $P_{3}\left[\mathbf{a}^{16}, \mathbf{b}^{51}, \mathbf{c}^{52}, \mathbf{d}^{20} \mathbf{e}^{53} \mathbf{f}^{54}\right]$ denoted by squares (single-crystalline values measured in experiments) and circles (single-crystalline values evaluated ${ }^{64}$ by using ceramic values measured in experiments) 

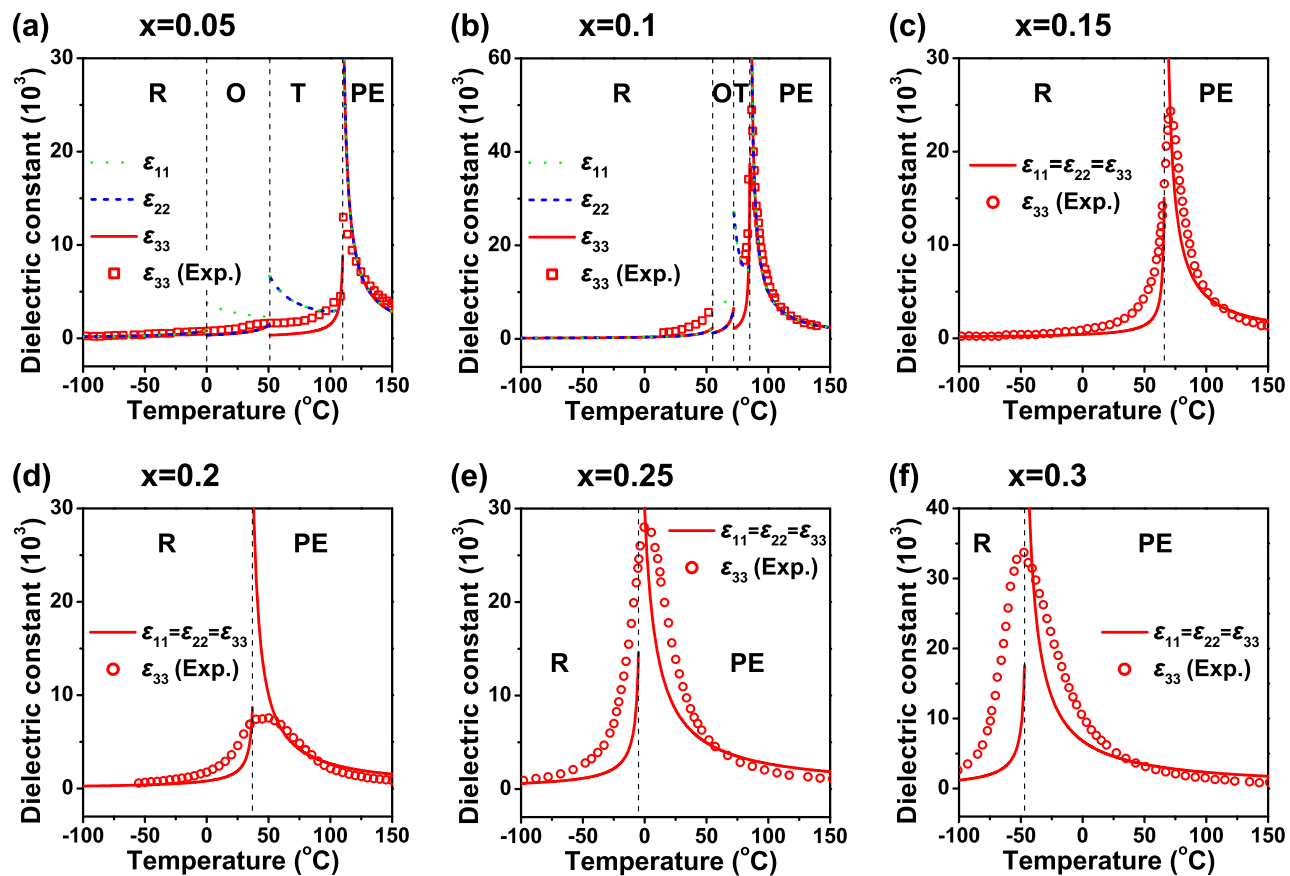

Fig. 2 Dielectric constants of $\mathrm{Ba}\left(\mathrm{Zr}_{x} \mathrm{Ti}_{1-x}\right) \mathrm{O}_{3}$ solid solutions as a function of temperature. $\mathbf{a} x=0.05, \mathbf{b} x=0.1, \mathbf{c} x=0.15, \mathbf{d} x=0.2, \mathbf{e} x=0.25$, and $\mathbf{f} x=0.3$, the experimental data of $\varepsilon_{33}\left[\mathbf{a}^{55} \mathbf{b}_{1}{ }^{19} \mathbf{c}^{56} \mathbf{d}^{57} \mathbf{e}\right.$, and $\mathbf{f}^{21}$ ] denoted by squares (single crystals) and circles (ceramics)
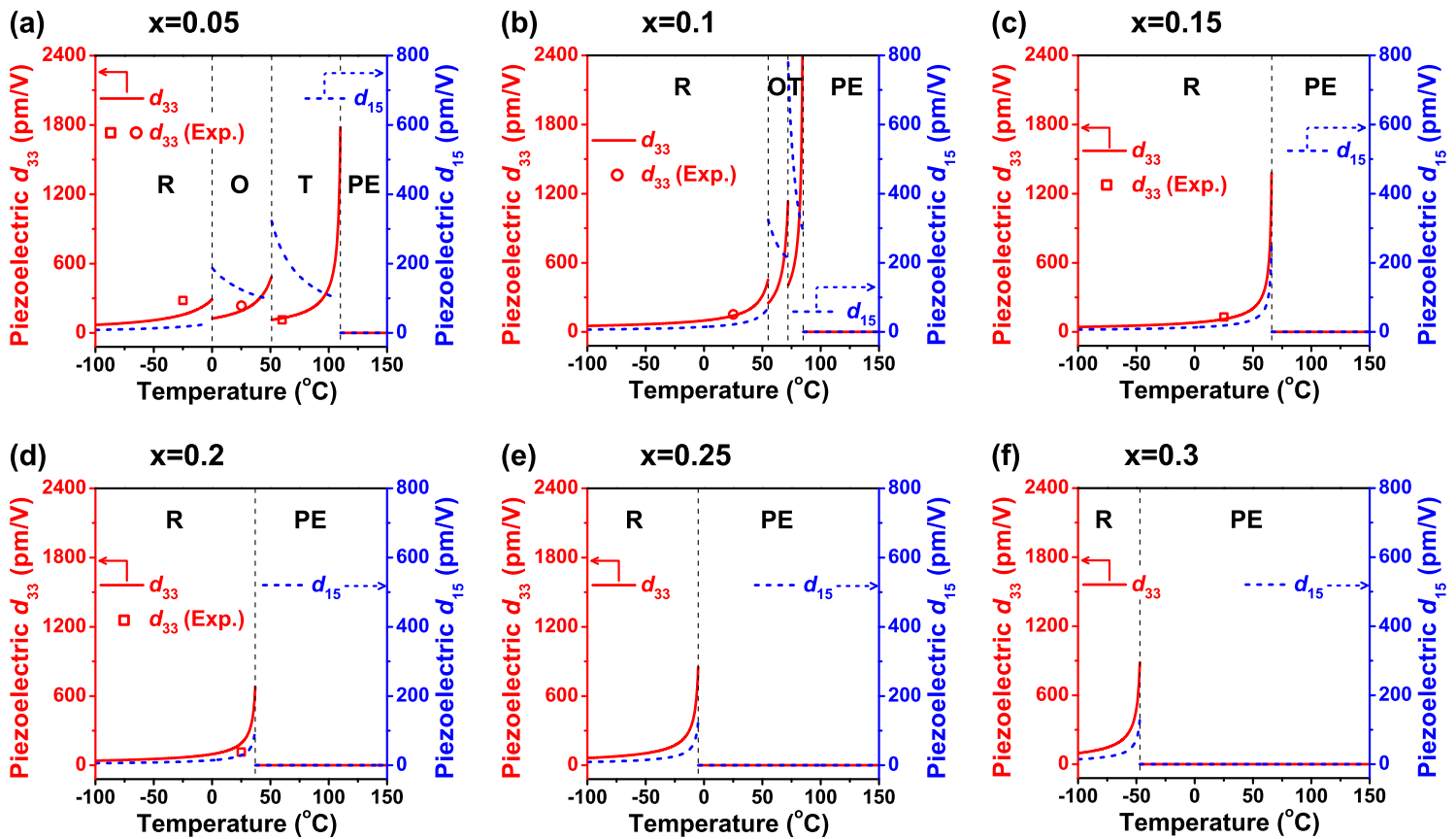

Fig. 3 Piezoelectric coefficients $d_{33}$ and $d_{15}$ of $\mathrm{Ba}\left(\mathrm{Zr}_{x} \mathrm{Ti}_{1-x}\right) \mathrm{O}_{3}$ solid solutions as a function of temperature. $\mathbf{a} x=0.05, \mathbf{b} x=0.1, \mathbf{c} x=0.15$, $\mathbf{d} x=$ 0.2 , e $x=0.25$, and $\mathbf{f} x=0.3$, the experimental data of $d_{33}\left[\mathbf{a}^{17,55} \mathbf{b}^{22} \mathbf{c}\right.$, and $\left.\mathbf{d}^{20}\right]$ denoted by squares (single crystals) and circles (ceramics)

Thermodynamic analysis

We now adopt the constructed thermodynamic potential to predict the phase structures and electromechanical properties of $\mathrm{Ba}\left(\mathrm{Zr}_{x} \mathrm{Ti}_{1-x}\right) \mathrm{O}_{3}$ solid solutions, including the variations of properties in both specific compositions and continuous variations of compositions, which are also compared with some reported experimental data for verifying the reliability of the established thermodynamic potential.
Phase structures and electromechanical properties in specific compositions

We first examine phase structures and electromechanical properties of $\mathrm{Ba}\left(\mathrm{Zr}_{x} \mathrm{Ti}_{1-x}\right) \mathrm{O}_{3}$ solid solutions in specific compositions, such as $\mathrm{Ba}\left(\mathrm{Zr}_{x} \mathrm{Ti}_{1-x}\right) \mathrm{O}_{3}$ with composition $x=0.05,0.1,0.15,0.2,0.25$, and 0.3 . The free energy of $\mathrm{Ba}\left(\mathrm{Zr}_{x} \mathrm{Ti}_{1-x}\right) \mathrm{O}_{3}$ solid solutions under stress-free boundary condition is plotted in Supplementary Fig. S3, according to which the energy minimizing phase structures are 
identified. Supplementary Fig. S3(a) indicates that $\mathrm{Ba}\left(\mathrm{Zr}_{x} \mathrm{Ti}_{1-x}\right) \mathrm{O}_{3}$ with the composition $x=0.05$ undergoes three phase transitions, and has a rhombohedral phase, an orthorhombic phase, a tetragonal phase, and a paraelectric phase in order of increasing temperature. A similar characteristic has been observed in $\mathrm{Ba}$ $\left(\mathrm{Zr}_{x} \mathrm{Ti}_{1-x}\right) \mathrm{O}_{3}$ with the composition $x=0.1$ [Supplementary Fig. S3 (b)], while the temperature range of rhombohedral phase extends, and the temperature ranges for orthorhombic and tetragonal phases shrink. For the composition $x=0.15$ [Supplementary Fig. S3(c)], all the phases have the same energy at $T_{C}$, suggesting a quadruple point in $\mathrm{Ba}\left(\mathrm{Zr}_{x} \mathrm{Ti}_{1-x}\right) \mathrm{O}_{3}$, which has been confirmed by experimental observations. ${ }^{15,16}$ For the composition $x=0.2,0.25$, 0.3 below the Curie temperature $T_{C}$ [Supplementary Figs. S3(d)(f)], the rhombohedral phase has the lowest energy though the contrast between the three ferroelectric phases is not obvious. The phase transition temperatures can also be identified, which are marked in Supplementary Fig. S3. We compare phase transition temperatures between calculations and experiments ${ }^{13,16-22,26,50}$ in Supplementary Table S2, and a good agreement between them is observed, suggesting that the constructed thermodynamic potential reproduces phase transitions in $\mathrm{Ba}\left(\mathrm{Zr}_{x} \mathrm{Ti}_{1-x}\right) \mathrm{O}_{3}$ solid solutions correctly.
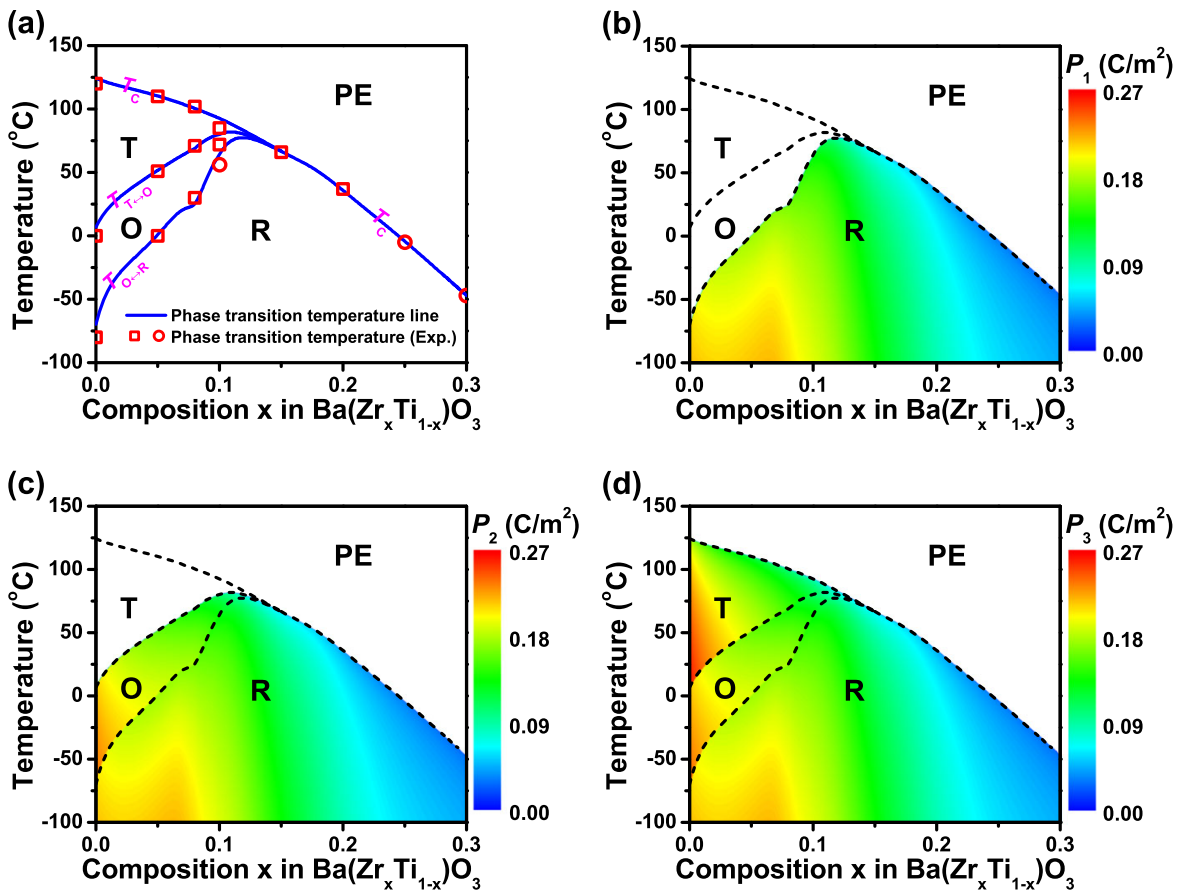

Based on the constructed thermodynamic potential, we also calculate the electromechanical properties of $\mathrm{Ba}\left(\mathrm{Zr}_{x} \mathrm{Ti}_{1-x}\right) \mathrm{O}_{3}$ solid solutions in specific compositions as a function of temperature, as shown in Figs. 1-3, in which some available experimental data from literatures are referred for comparison. Figure 1 reveals that the modulus of polarization decreases with an increase in temperature as expected, while the polarization components show discontinuous variations across phase boundaries, suggesting $\mathrm{Ba}\left(\mathrm{Zr}_{x} \mathrm{Ti}_{1-x}\right) \mathrm{O}_{3}$ solid solutions having first-order phase transition. At the same temperature, the magnitude of polarization decreases with an increase in composition $x$. The experimental data for polarization of $\mathrm{Ba}\left(\mathrm{Zr}_{x} \mathrm{Ti}_{1-x}\right) \mathrm{O}_{3}$ single-crystalline at some compositions is unavailable. For this case, we evaluate the singlecrystalline polarization values $P_{3}$ by using its counterpart ceramic values $P_{3}^{c}$ measured in experiments for comparison. The used relationships between them are $P_{3}=3 P_{3}^{c}$ in tetragonal phase and $P_{3}=\sqrt{2} P_{3}^{c}$ in rhombohedral phase ${ }^{64}$ (details in the Supporting Information). The values of polarization calculated based on thermodynamic theory are consistent with those measured in experiments, ${ }^{16,20,51-54}$ as evidenced in Fig. 1 . The dielectric and piezoelectric responses show peaks at phase transition temperatures, as seen in Figs. 2 and 3, especially a high electromechanical
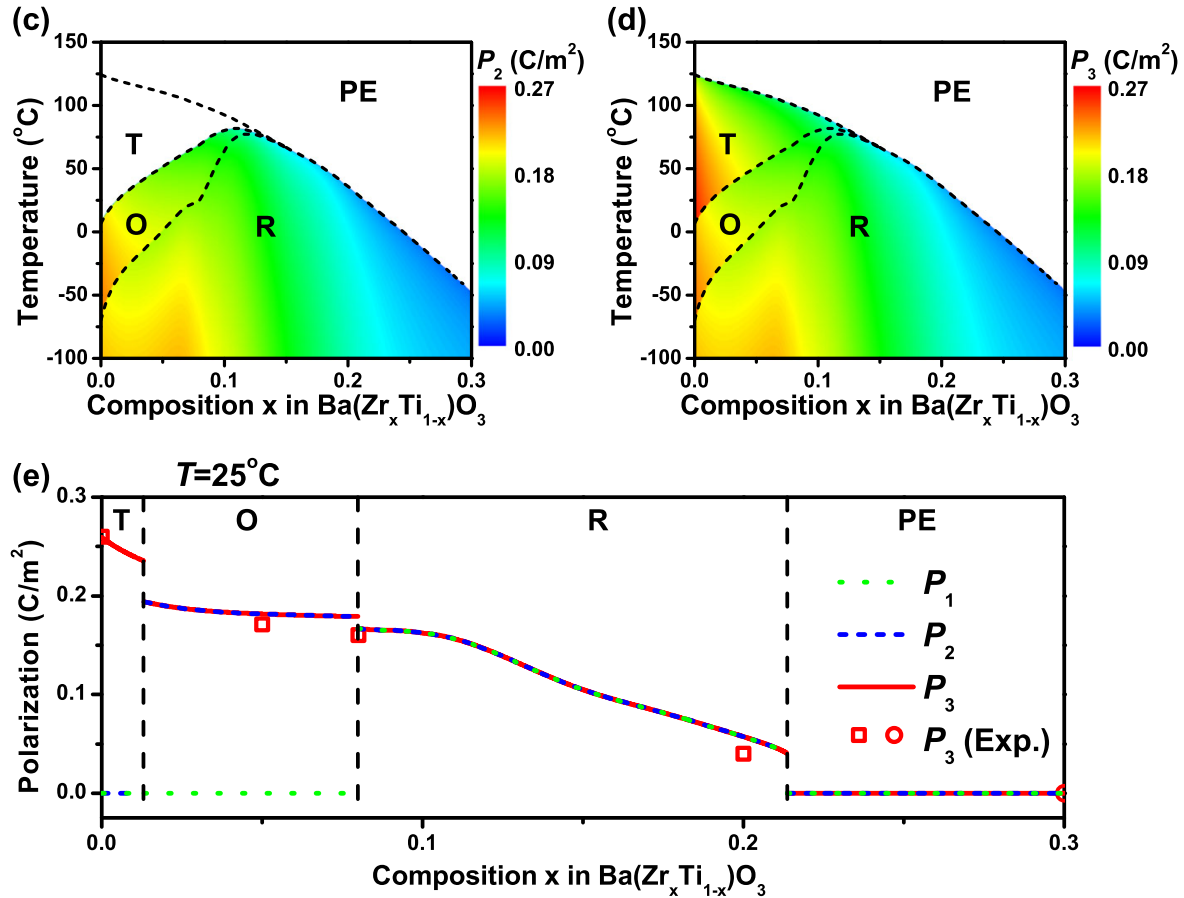

Fig. 4 a Temperature-composition phase diagram of $\mathrm{Ba}\left(\mathrm{Zr}_{\gamma} \mathrm{Ti}_{1-x}\right) \mathrm{O}_{3}$ solid solutions, the experimental phase transition temperatures denoted by squares (single crystals) ${ }^{13,16,18-20}$ and circles (ceramics). ${ }^{1 Y, 21,22}$ Polarization $\mathbf{b} P_{1}, \mathbf{c} P_{2}$, and $\mathbf{d} P_{3}$ of $\mathrm{Ba}\left(\mathrm{Zr}_{x} \mathrm{Ti}_{1-x}\right) \mathrm{O}_{3}$ solid solutions as a function of composition $x$ and temperature. The phase transition temperature lines are also marked. e the polarization as a function of composition $x$ at room temperature, the experimental data of $P_{3}$ denoted by squares (single-crystalline values measured in experiments) ${ }^{16,18,20,65}$ and circles (single-crystalline values evaluated ${ }^{64}$ by using ceramic values measured in experiments) ${ }^{54}$ 
(a)

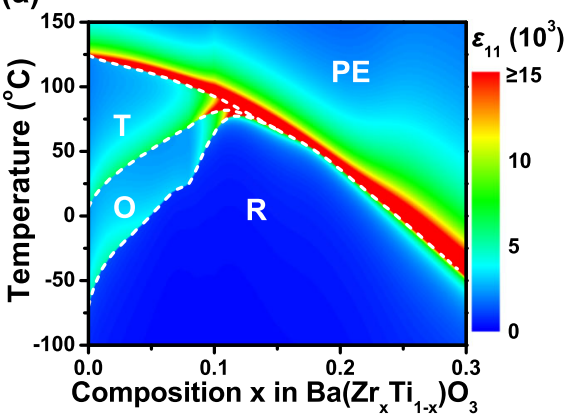

(c)

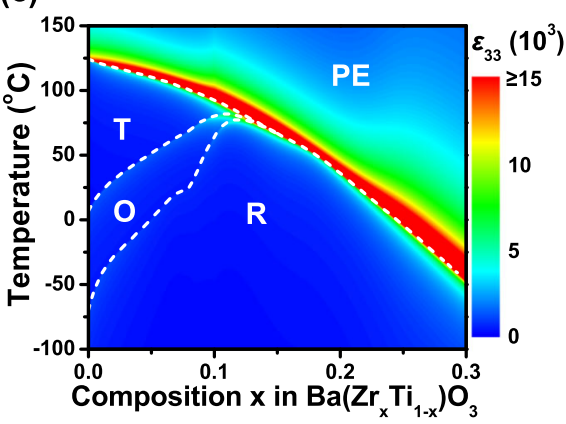

(b)

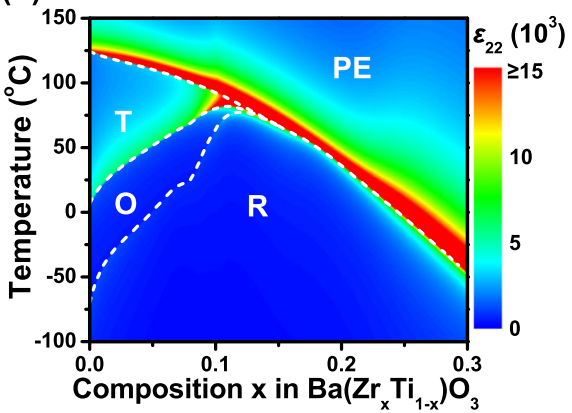

(d)

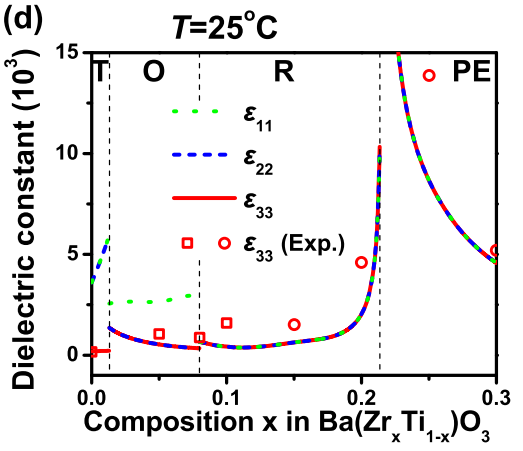

Fig. 5 Dielectric constants $\mathbf{a} \varepsilon_{11}, \mathbf{b} \varepsilon_{22}$, and $\mathbf{c} \varepsilon_{33}$ of $\mathrm{Ba}\left(\mathrm{Zr}_{x} \mathrm{Ti}_{1-x}\right) \mathrm{O}_{3}$ solid solutions as a function of composition $x$ and temperature. The phase transition temperature lines are also marked. $\mathbf{d}$ the dielectric constant as a function of composition $x$ at room temperature, the experimental data of $\varepsilon_{33}$ denoted by squares (single crystals) ${ }^{18,19,55,66}$ and circles (ceramics) $)^{21,56,57}$

(a)

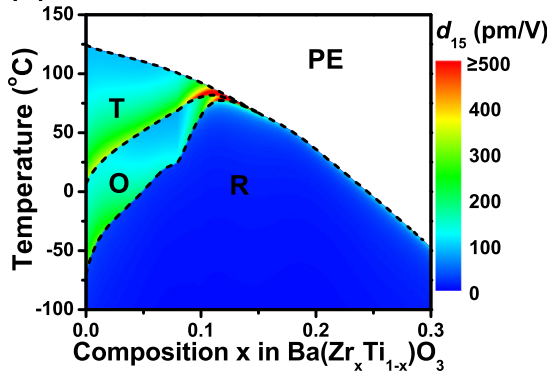

(d)

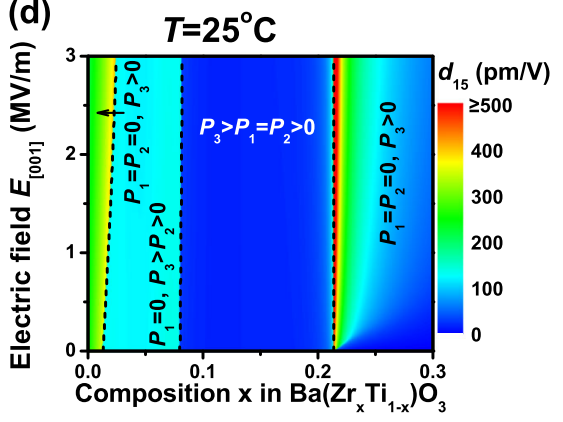

(b)

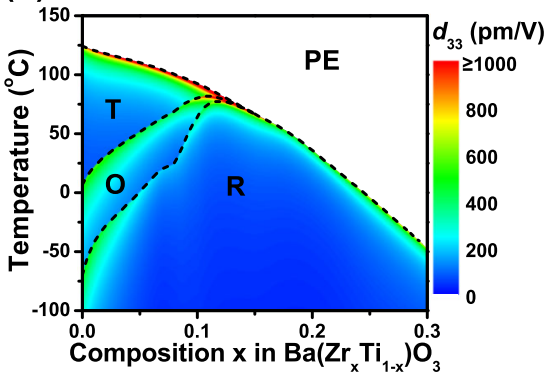

(e)

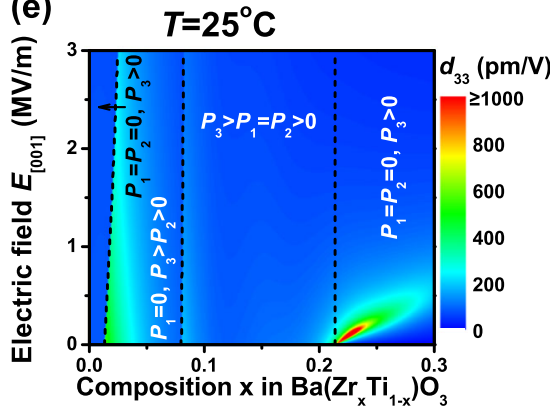

(c)

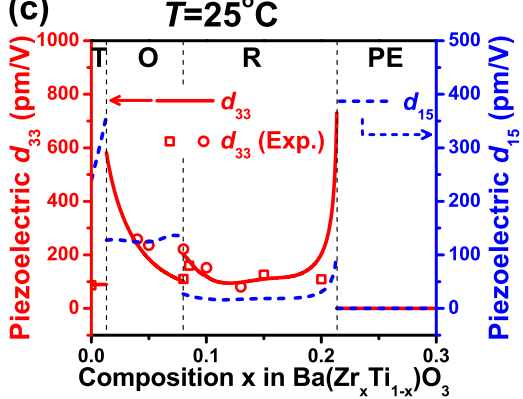

(f)

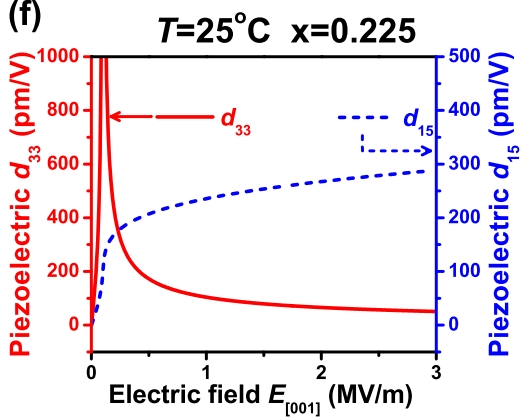

Fig. 6 Piezoelectric coefficients $\mathbf{a} d_{15}$, and $\mathbf{b} d_{33}$ of $\mathrm{Ba}\left(\mathrm{Zr}_{x} \mathrm{Ti}_{1-x}\right) \mathrm{O}_{3}$ solid solutions as a function of composition $x$ and temperature. The phase transition temperature lines are also marked. c the piezoelectric coefficient as a function of composition $x$ at room temperature, the experimental data of $d_{33}$ denoted by squares (single crystals) ${ }^{20,55,66,67}$ and circles (ceramics). ${ }^{17,22} \mathbf{d} d_{15}$ and e $d_{33}$ as a function of composition $x$ and electric field (E along [001] direction) at room temperature, and $\mathbf{f}$ the corresponding piezoelectric coefficients for the case $x=0.225$

response existing at ferroelectric-paraelectric phase transition temperature, implying that superior electromechanical properties always appear near phase boundaries. The experimental data of $\varepsilon_{33}{ }^{19,21,55-57}$ and $d_{33}{ }^{17,20,22,55}$ are also plotted in Figs. 2 and 3, showing that our thermodynamic calculation results agree with experimental data. For some composition $x$, the obvious differences between the calculation values and experimental measurements can be observed, since the counterpart ceramic values are used for comparison due to the lack of experimental data for the corresponding single crystals. All the above 
comparisons between thermodynamic calculations and experimental data, including the comparisons of phase structures, phase transition temperatures, and electromechanical properties, suggest that the constructed thermodynamic potential of $\mathrm{Ba}\left(\mathrm{Zr}_{x} \mathrm{Ti}_{1-x}\right)$ $\mathrm{O}_{3}$ solid solutions is reliable.

Phase diagram and electromechanical properties of continuous variations of compositions

In order to study the compositional dependence of phase structures and electromechanical properties, we fit the correlations between thermodynamic potential coefficients (Table 1) and composition $x$ of $\mathrm{Ba}\left(\mathrm{Zr}_{x} \mathrm{Ti}_{1-x}\right) \mathrm{O}_{3}$ solid solutions, as shown in Supplementary Fig. S4, the corresponding expressions of the fitting curves are listed in Supplementary Table S3. Based on these expressions of the thermodynamic potential coefficients, the temperature-composition phase diagram of $\mathrm{Ba}\left(\mathrm{Zr}_{x} \mathrm{Ti}_{1-x}\right) \mathrm{O}_{3}$ solid solutions is constructed in Fig. $4 a$ by searching for the lowest energy state between different phases. It exhibits that a paraelectric phase locates at high temperature, and a rhombohedral ferroelectric phase occupies in low temperature range, while tetragonal and orthorhombic ferroelectric phases appear only between paraelectric and rhombohedral phases at low composition $x$. Also, it can be found that the Curie temperature $T_{C}$ decreases with an increase in composition $x$, while phase transition temperatures $T_{\mathrm{T} \leftrightarrow \mathrm{O}}$ and $T_{\mathrm{O} \leftrightarrow \mathrm{R}}$ show an opposite trend, and both of them increase with increasing composition $x$, leading to a pinched phase transition and a quadruple point near $x=0.15$, as shown in Fig. 4a. The experimental phase transition temperatures reported in literature ${ }^{13,16-22}$ are marked in Fig. 4a for comparison, indicating that our calculation results are consistent with experimental results, which again confirms the reliability of thermodynamic potential constructed in this work.

The contour plot of polarization components in terms of composition and temperature is shown in Figs. $4 \mathrm{~b}-\mathrm{d}$. It can be observed that $\mathrm{Ba}\left(\mathrm{Zr}_{x} \mathrm{Ti}_{1-x}\right) \mathrm{O}_{3}$ solid solutions with a low composition $x$ have high polarization, and the polarization components are discontinuous at phase boundaries, which implies first-order phase transitions in $\mathrm{Ba}\left(\mathrm{Zr}_{x} \mathrm{Ti}_{1-x}\right) \mathrm{O}_{3}$ solid solutions. The contour plots of dielectric constants and piezoelectric coefficients are also presented in Figs. $5 a-c$ and Figs. $6 a-b$, respectively, where the anomalies of dielectric and piezoelectric responses are observed around the phase boundaries, and superior dielectric and piezoelectric properties appear near the ferroelectric-paraelectric phase boundary, especially around quadruple point. To see this more clearly, the corresponding polarization, dielectric constants and piezoelectric coefficients at room temperature are given in Figs. $4 \mathrm{e}, 5 \mathrm{~d}$, and $6 \mathrm{c}$. It is noticed that the tetragonal-orthorhombic (ferroelectric-ferroelectric) phase boundary is at $x=0.013$, the orthorhombic-rhombohedral (ferroelectric-ferroelectric) phase boundary is located at $x=0.0798$, and the rhombohedral-paraelectric (ferroelectric-paraelectric) phase boundary is at $x=0.2135$. The dielectric and piezoelectric properties show peaks near the tetragonal-orthorhombic (ferroelectric-ferroelectric) and rhombohedral-paraelectric (ferroelectric-paraelectric) phase boundaries. Comparing the electromechanical properties among the three phase boundaries, it is evident that the ferroelectric-paraelectric phase boundary has more superior electromechanical properties, suggesting a new way to enhance electromechanical coupling in $\mathrm{Ba}\left(\mathrm{Zr}_{x} \mathrm{Ti}_{1-x}\right) \mathrm{O}_{3}$ solid solutions. In addition, good agreements between calculated results and experimental data are observed in Figs. 4e, 5d, and $6 c$. We also examine the effect of electric field on piezoelectric coefficients at room temperature in Figs. $6 \mathrm{~d}-\mathrm{f}$, where electric field induced the enhancement of piezoelectric response is obvious, especially at high composition $x$ (for example, $x=0.225$ ) near the ferroelectric-paraelectric phase boundary.
In summary, we have constructed a thermodynamic potential for $\mathrm{Ba}\left(\mathrm{Zr}_{x} \mathrm{Ti}_{1-x}\right) \mathrm{O}_{3}$ solid solutions, and carried out the thermodynamic analysis of $\mathrm{Ba}\left(\mathrm{Zr}_{x} \mathrm{Ti}_{1-x}\right) \mathrm{O}_{3}$ solid solutions using the constructed thermodynamic potential. It is found that the phase structures, phase transition temperatures, polarization, dielectric, and piezoelectric properties of $\mathrm{Ba}\left(\mathrm{Zr}_{x} \mathrm{Ti}_{1-x}\right) \mathrm{O}_{3}$ solid solutions are reproduced well. The results also reveal that three phase boundaries, including tetragonal-orthorhombic, orthorhombic-rhombohedral, and rhombohedral-paraelectric phase boundaries, can be formed at different chemical compositions. The chemical composition-induced ferroelectric-paraelectric phase boundary has superior electromechanical properties, which suggests a new way to enhance electromechanical coupling in $\mathrm{Ba}$ $\left(\mathrm{Zr}_{x} \mathrm{Ti}_{1-x}\right) \mathrm{O}_{3}$ solid solutions. Notice that stress and strain constraints are always used to tune the phase structures and electromechanical properties in ferroelectrics. ${ }^{39,68}$ The constructed thermodynamic potential can be also used to predict the changes in phase structures and electromechanical properties under mechanical constraints.

\section{METHODS}

The process of determining thermodynamic potential coefficients for $\mathrm{Ba}$ $\left(\mathrm{Zr}_{x} \mathrm{Ti}_{1-x}\right) \mathrm{O}_{3}$ solid solutions is schematically illustrated in Supplementary Fig. S1. Among all thermodynamic potential coefficients, only $a_{1}$ is assumed to be dependent on temperature $T$, following Curie-Weiss law

$a_{1}=\frac{T-T_{0}}{2 \varepsilon_{0} C}=a_{1}^{*}\left(T-T_{0}\right)$,

where $C, T_{0}$ are the Curie constant and Curie-Weiss temperature, respectively. $a_{1}$ can be determined by fitting Curie temperature $T_{\mathrm{C}}$ and dielectric constants of paraelectric phase in $\mathrm{Ba}\left(\mathrm{Zr}_{x} \mathrm{Ti}_{1-x}\right) \mathrm{O}_{3}$ solid solutions, as shown in Supplementary Fig. S1. The thermodynamic potential coefficients $a_{11}, a_{111}$, and $a_{1111}$ need to be fitted to the phase transition temperatures $T_{\mathrm{C}}$ and $T_{\mathrm{T} \leftrightarrow \mathrm{O}}$, as well as dielectric constant and polarization of tetragonal phase. The coefficients $a_{12}, a_{112}, a_{1112}$, and $a_{1122}$ are fitted to the phase transition temperatures $T_{\mathrm{T} \leftrightarrow \mathrm{O}}$ and $T_{\mathrm{O} \leftrightarrow \mathrm{R}}$, and dielectric constant and polarization of orthorhombic phase. Similarly, the coefficients $a_{123}$ and $a_{1123}$ can estimated via fitting the phase transition temperature $T_{\mathrm{O} \leftrightarrow \mathrm{R}}$ and electrical properties in rhombohedral phase. After that, all the thermodynamic potential coefficients of $\mathrm{Ba}\left(\mathrm{Zr}_{x} \mathrm{Ti}_{1-x}\right) \mathrm{O}_{3}$ solid solutions can be obtained, as tabulated in Table 1. It is noted that the experimental observations ${ }^{17,20,21}$ indicated only paraelectric and rhombohedral two phases existing in $\mathrm{Ba}\left(\mathrm{Zr}_{x} \mathrm{Ti}_{1-x}\right) \mathrm{O}_{3}$ solid solutions with high concentration of $\mathrm{Zr}(x>0.15)$. For this reason, the experimental data of paraelectric and rhombohedral phases is used to determine thermodynamic potential coefficients at high concentration $x_{1}$ as well as the eighth-order thermodynamic potential coefficients $a_{1111}, a_{1112}, a_{1122}$, and $a_{1123}$ are set to be zero for this case.

\section{DATA AVAILABILITY}

The data that support the findings of this study are available from the corresponding author upon reasonable request.

\section{ACKNOWLEDGEMENTS}

This work was partially supported by the National Key Research and Development Program of China (2016YFA0201001), NSFC (Approval Nos. 11572276, 11772286, 11502225,11627801 , and 11402221), Project supported by Hunan Provincial Natural Science Foundation of China (2017JJ3312 and 2016JJ6146), Scientific Research Fund of Hunan Provincial Education Department (16A202 and 17B251), and Hunan Provincial Innovation Foundation for Postgraduate (CX2017B279). Lei acknowledges startup fund supported jointly by the Dean of Parks College and the Provost of the Saint Louis University.

\section{AUTHOR CONTRIBUTIONS}

Y.L. conceived the idea and designed the calculations. Y.L. and J.P. implemented constructing thermodynamic potential. Q.Y. calculated electrostrictive coefficients. All authors performed thermodynamic analysis. Y.L. and J.P. analyzed the results and wrote the paper. All authors reviewed and contributed to the final paper preparation. 


\section{ADDITIONAL INFORMATION}

Supplementary information accompanies the paper on the npj Computational Materials website (https://doi.org/10.1038/s41524-018-0126-3).

Competing interests: The authors declare no competing interests.

Publisher's note: Springer Nature remains neutral with regard to jurisdictional claims in published maps and institutional affiliations.

\section{REFERENCES}

1. Li, F. et al. Ultrahigh piezoelectricity in ferroelectric ceramics by design. Nat. Mater. 17, 349-354 (2018).

2. Hong, Z. J. et al. Stability of polar vortex lattice in ferroelectric superlattices. Nano Lett. 17, 2246-2252 (2017).

3. Schlom, D. G. et al. Strain tuning of ferroelectric thin films. Annu. Rev. Mater. Res. 37, 589-626 (2007).

4. Cao, S. G. et al. Stress-induced cubic-to-hexagonal phase transformation in perovskite nanothin films. Nano Lett. 17, 5148-5155 (2017)

5. Velev, J. P., Burton, J. D., Zhuravlev, M. Y. \& Tsymbal, E. Y. Predictive modelling of ferroelectric tunnel junctions. npj Comput. Mater. 2, 16009 (2016).

6. Sharma, P. et al. Nonvolatile ferroelectric domain wall memory. Sci. Adv. 3, e1700512 (2017).

7. Scott, J. F. Electrocaloric materials. Annu. Rev. Mater. Res. 41, 229-240 (2011).

8. Wu, H. H., Zhu, J. M. \& Zhang, T. Y. Pseudo-first-order phase transition for ultrahigh positive/negative electrocaloric effects in perovskite ferroelectrics. Nano Energy 16, 419-427 (2015).

9. Tang, Y. L. et al. Observation of a periodic array of flux-closure quadrants in strained ferroelectric $\mathrm{PbTiO}_{3}$ films. Science 348, 547-551 (2015).

10. Wu, H. H. \& Cohen, R. E. Electric-field-induced phase transition and electrocaloric effect in PMN-PT. Phys. Rev. B 96, 054116 (2017).

11. Ma, R. J. et al. Nonvolatile ferroelectric domain wall memory. Science 357, 1130-1134 (2017).

12. Zheng, Y., Cai, M. Q. \& Woo, C. H. Critical properties of symmetric nanoscale metal-ferroelectric-metal capacitors. Acta Mater. 58, 3050-3058 (2010).

13. Merz, W. J. The electric and optical behavior of $\mathrm{BaTiO}_{3}$ single-domain crystals. Phys. Rev. 76, 1221-1225 (1949).

14. McQuarrie, M. \& Behnke, F. W. Structural and dielectric studies in the system (Ba, Ca)(Ti,Zr)O ${ }_{3}$. J. Am. Ceram. Soc. 37, 539-543 (1954).

15. Maiti, T., Guo, R. Y. \& Bhalla, A. S. Structure-property phase diagram of $\mathrm{BaZr}_{\mathrm{x}} \mathrm{Ti}_{1}$ ${ }_{\mathrm{x}} \mathrm{O}_{3}$ system. J. Am. Ceram. Soc. 91, 1769-1780 (2008).

16. Yu, Z., Guo, R. Y. \& Bhalla, A. S. Dielectric behavior of $\mathrm{Ba}\left(\mathrm{Ti}_{1-\mathrm{x}} \mathrm{Zr}_{\mathrm{x}}\right) \mathrm{O}_{3}$ single crystals. J. Appl. Phys. 88, 410-415 (2000).

17. Yu, Z., Ang, C., Guo, R. Y. \& Bhalla, A. S. Piezoelectric and strain properties of $\mathrm{Ba}\left(\mathrm{Ti}_{1}\right.$ $\left.{ }_{x} \mathrm{Zr}_{x}\right) \mathrm{O}_{3}$ ceramics. J. Appl. Phys. 92, 1489-1493 (2002)

18. Yu, Z., Guo, R. Y. \& Bhalla, A. S. Dielectric polarization and strain behavior of $\mathrm{Ba}$ $\left(\mathrm{Ti}_{0.92} \mathrm{Zr}_{0.08}\right) \mathrm{O}_{3}$ single crystals. Mater. Lett. 57, 349-354 (2002).

19. Lee, H. Y. 6-Development of high-performance piezoelectric single crystals by using solid-state single crystal growth (SSCG) method. In Ye, Z. G. (eds.) Handbook of Advanced Dielectric, Piezoelectric and Ferroelectric Materials, Woodhead Publishing Series in Electronic and Optical Materials, 158-172 (Woodhead Publishing, Cambridge, England, 2008).

20. Yu, Z., Guo, R. Y. \& Bhalla, A. S. Growth of $\mathrm{Ba}\left(\mathrm{Ti}_{1-\mathrm{x}} \mathrm{Zr}_{\mathrm{x}}\right) \mathrm{O}_{3}$ single crystal fibers by laser heated pedestal growth technique. Ferroelectr. Lett. Sect. 27, 113-123 (2000).

21. Yu, Z., Chen, A., Guo, R. Y. \& Bhalla, A. S. Dielectric properties of $B a\left(\mathrm{Ti}_{1-x} \mathrm{Zr}_{\mathrm{x}}\right) \mathrm{O}_{3}$ solid solutions. Mater. Lett. 61, 326-329 (2007).

22. Kalyani, A. K., Senyshyn, A. \& Ranjan, R. Polymorphic phase boundaries and enhanced piezoelectric response in extended composition range in the lead free ferroelectric $\mathrm{Ba}\left(\mathrm{Ti}_{1-\mathrm{x}} \mathrm{Zr}_{\mathrm{x}}\right) \mathrm{O}_{3}$. J. Appl. Phys. 114, 014102 (2013).

23. Qian, X. S. et al. Giant electrocaloric response over a broad temperature range in modified $\mathrm{BaTiO}_{3}$ ceramics. Adv. Funct. Mater. 24, 1300-1305 (2014).

24. Devonshire, A. F. XCVI. Theory of barium titanate Part I. Philos. Mag. 40, 1040-1063 (1949).

25. Marton, P., Rychetsky, I. \& Hlinka, J. Domain walls of ferroelectric $\mathrm{BaTiO}_{3}$ within the Ginzburg-Landau-Devonshire phenomenological model. Phys. Rev. B 81, 144125 (2010).

26. Li, Y. L., Cross, L. E. \& Chen, L. Q. A phenomenological thermodynamic potential for $\mathrm{BaTiO}_{3}$ single crystals. J. Appl. Phys. 98, 064101 (2005).

27. Khakpash, N., Khassaf, H., Rossetti, G. A. Jr. \& Alpay, S. P. Misfit strain phase diagrams of epitaxial PMN-PT films. Appl. Phys. Lett. 106, 082905 (2015).

28. Wang, J. \& Zhang, T. Y. Effects of nonequally biaxial misfit strains on the phase diagram and dielectric properties of epitaxial ferroelectric thin films. Appl. Phys. Lett. 86, 192905 (2005).
29. Pertsev, N. A., Zembilgotov, A. G. \& Tagantsev, A. K. Effect of mechanical boundary conditions on phase diagrams of epitaxial ferroelectric thin films. Phys. Rev. Lett. 80, 1988-1991 (1998).

30. Pertsev, N. A. \& Kohlstedt, H. Elastic stabilization of a single-domain ferroelectric state in nanoscale capacitors and tunnel junctions. Phys. Rev. Lett. 98, 257603 (2007).

31. Lv, P., Wang, L. H. \& Lynch, C. S. A phenomenological thermodynamic energy function for PIN-PMN-PT relaxor ferroelectric single crystals. Acta Mater. 137, 93-102 (2017).

32. Qiu, Y. et al. Giant electrocaloric effect in ferroelectric ultrathin films at room temperature mediated by flexoelectric effect and work function. J. Appl. Phys. 122, 024103 (2017).

33. Mangeri, J., Pitike, K. C., Alpay, S. P. \& Nakhmanson, S. Amplitudon and phason modes of electrocaloric energy interconversion. npj Comput. Mater. 2, 16020 (2016).

34. Liu, Y. Y. et al. Controlling magnetoelectric coupling by nanoscale phase transformation in strain engineered bismuth ferrite. Nanoscale 4, 3175-3183 (2012).

35. Karpinsky, D. V. et al. Thermodynamic potential and phase diagram for multiferroic bismuth ferrite $\left(\mathrm{BiFeO}_{3}\right.$ ). npj Comput. Mater. 3, 20 (2017).

36. Haun, M. J., Zhuang, Z. Q., Furman, E., Jang, S. J. \& Cross, L. E. Thermodynamic theory of the lead zirconatetitanate solid solution system, part III: Curie constant and sixth-order polarization interaction dielectric stiffness coefficients. Ferroelectrics 99, 45-54 (1989).

37. Bell, A. J. \& Cross, L. E. A phenomenological gibbs function for $\mathrm{BaTiO}_{3}$ giving correct e field dependence of all ferroelectric phase changes. Ferroelectrics 59, 197-203 (1984).

38. Wang, Y. L. et al. Landau thermodynamic potential for $\mathrm{BaTiO}_{3}$. J. Appl. Phys. 101, 104115 (2007)

39. Wang, J. J., Wu, P. P., Ma, X. Q. \& Chen, L. Q. Temperature-pressure phase diagram and ferroelectric properties of $\mathrm{BaTiO}_{3}$ single crystal based on a modified Landau potential. J. Appl. Phys. 108, 114105 (2010).

40. Salahuddin, S. \& Datta, S. Use of negative capacitance to provide voltage amplification for low power nanoscale devices. Nano Lett. 8, 405-410 (2008).

41. Karthik, J. \& Martin, L. W. Pyroelectric properties of polydomain epitaxial $\mathrm{Pb}\left(\mathrm{Zr}_{1-\mathrm{x}}\right.$ $\left.\mathrm{Ti}_{\mathrm{x}}\right) \mathrm{O}_{3}$ thin films. Phys. Rev. B 84, 024102 (2011).

42. Liu, Y. Y. \& Li, J. Y. Shear-driven morphotropic phase boundary in epitaxial ferroelectric thin films. Phys. Rev. B 84, 132104 (2011).

43. Li, Y. L. \& Chen, L. Q. Temperature-strain phase diagram for $\mathrm{BaTiO}_{3}$ thin films. Appl. Phys. Lett. 88, 072905 (2006).

44. Chen, L. Q. Phase-field method of phase transitions/domain structures in ferroelectric thin films: A review. J. Am. Ceram. Soc. 91, 1835-1844 (2008).

45. Wang, J., Li, Y. L., Chen, L. Q. \& Zhang, T. Y. The effect of mechanical strains on the ferroelectric and dielectric properties of a model single crystal - phase field simulation. Acta Mater. 53, 2495-2507 (2005)

46. Su, Y., Liu, N. \& Weng, G. J. A phase field study of frequency dependence and grain-size effects in nanocrystalline ferroelectric polycrystals. Acta Mater. 87, 293-308 (2015)

47. Haun, M. J., Furman, E., Jang, S. J., McKinstry, H. A. \& Cross, L. E. Thermodynamic theory of $\mathrm{PbTiO}_{3}$. J. Appl. Phys. 62, 3331-3338 (1987).

48. Liu, Y. Y., Zhu, Z. X., Li, J. F. \& Li, J. Y. Misfit strain modulated phase structures of epitaxial $\mathrm{Pb}\left(\mathrm{Zr}_{1-x} \mathrm{Ti}_{x}\right) \mathrm{O}_{3}$ thin films: The effect of substrate and film thickness. Mech. Mater. 42, 816-826 (2010).

49. Liu, Y. Y., Yang, L. \& Li, J. Y. Strain-engineered orthorhombic-rhombohedral phase boundary in epitaxial bismuth ferrite films. J. Appl. Phys. 113, 183524 (2013).

50. Peng, J. L. et al. Phenomenological thermodynamic potentials for bulk and thinfilm $\mathrm{Ba}\left(\mathrm{Zr}_{0.08} \mathrm{Ti}_{0.92}\right) \mathrm{O}_{3}$ single crystals. J. Appl. Phys. 119, 204103 (2016).

51. Tian, Y., Chao, X. L., Wei, L. L., Liang, P. F. \& Yang, Z. P. Phase transition behavior and electrical properties of lead-free $\left(\mathrm{Ba}_{1-\mathrm{x}} \mathrm{Ca}_{\mathrm{x}}\right)\left(\mathrm{Zr}_{0.1} \mathrm{Ti}_{0.9}\right) \mathrm{O}_{3}$ piezoelectric ceramics. J. Appl. Phys. 113, 184107 (2013).

52. Mahesh, M. L. V., Prasad, V. V. B. \& James, A. R. Enhanced dielectric and ferroelectric properties of lead-free $\mathrm{Ba}\left(\mathrm{Zr}_{0.15} \mathrm{Ti}_{0.85}\right) \mathrm{O}_{3}$ ceramics compacted by cold isostatic pressing. J. Alloy. Compd. 611, 43-49 (2014).

53. Kruea-In, C., Eitssayeam, S., Pengpat, K., Rujijanagul, G. \& Tunkasiri, T. Effects of vibro-milling on relaxor ferroelectric behavior and phase transition of lead-free $\mathrm{Ba}$ $\left(\mathrm{Zr}_{0.25} \mathrm{Ti}_{0.75}\right) \mathrm{O}_{3}$ ceramics. Phase Transit. 83, 942-949 (2010).

54. Yu, Z., Ang, C., Guo, R. Y. \& Bhalla, A. S. Ferroelectric-relaxor behavior of Ba $\left(\mathrm{Ti}_{0.7} \mathrm{Zr}_{0.3}\right) \mathrm{O}_{3}$ ceramics. J. Appl. Phys. 92, 2655-2657 (2002).

55. Yu, Z., Guo, R. Y. \& Bhalla, A. S. Orientation dependence of the ferroelectric and piezoelectric behavior of $\mathrm{Ba}\left(\mathrm{Ti}_{1-x} \mathrm{Zr}_{x}\right) \mathrm{O}_{3}$ single crystals. Appl. Phys. Lett. 77, 1535-1537 (2000).

56. Bao, H. X., Zhou, C., Xue, D. Z., Gao, J. H. \& Ren, X. B. A modified lead-free

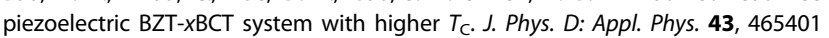
(2010).

57. Fu, C. L., Pan, F. S., Cai, W., Deng, X. L. \& Liu, X. W. Microstructures and dielectric properties of $\mathrm{BaZr}_{0.2} \mathrm{Ti}_{0.8} \mathrm{O}_{3}$ ceramics. J. Phys.: Conf. Ser. 152, 012075 (2009). 
58. Pohlmann, H., Wang, J. J., Wang, B. \& Chen, L. Q. A thermodynamic potential and the temperature-composition phase diagram for single-crystalline $\mathrm{K}_{1-x} \mathrm{Na}_{x} \mathrm{NbO}_{3}$ $(0 \leq \mathrm{x} \leq 0.5)$. Appl. Phys. Lett. 110, 102906 (2017).

59. Huang, Y. H. et al. A thermodynamic potential, energy storage performances, and electrocaloric effects of $\mathrm{Ba}_{1-x} \mathrm{Sr}_{\mathrm{x}} \mathrm{TiO}_{3}$ single crystals. Appl. Phys. Lett. 112, 102901 (2018).

60. Shakhovoy, R. A., Shirokov, V. B. \& Yuzyuk, Y. I. Phase diagrams of $\mathrm{BaTiO}_{3} / \mathrm{BaZrO}_{3}$ superlattices. Ferroelectrics 444, 168-176 (2013).

61. Yamada, T. Electromechanical properties of oxygen-octahedra ferroelectric crystals. J. Appl. Phys. 43, 328-338 (1972).

62. Wang, J. J., Meng, F. Y., Ma, X. Q., Xu, M. X. \& Chen, L. Q. Lattice, elastic, polarization, and electrostrictive properties of $\mathrm{BaTiO}_{3}$ from first-principles. J. Appl. Phys. 108, 034107 (2010)

63. Hayward, S. A. \& Salje, E. K. H. The pressure-temperature phase diagram of $\mathrm{BaTiO}_{3}$ : a macroscopic description of the low-temperature behaviour. J. Phys.: Condens. Matter 14, L599-L604 (2002).

64. Li, J. Y., Rogan, R. C., Üstündag, E. \& Bhattacharya, K. Domain switching in polycrystalline ferroelectric ceramics. Nat. Mater. 4, 776-781 (2005).

65. Wieder, H. H. Electrical behavior of barium titanatge single crystals at low temperatures. Phys. Rev. 99, 1161-1165 (1955).

66. Berlincourt, D. \& Jaffe, H. Elastic and piezoelectric coefficients of single-crystal barium titanate. Phys. Rev. 111, 143-148 (1958).
67. Rehrig, P. W. et al. Piezoelectric properties of zirconium-doped barium titanate single crystals grown by templated grain growth. J. Appl. Phys. 86, 1657-1661 (1999).

68. Zhou, M. J., Wang, J. J., Chen, L. Q. \& Nan, C. W. Strain, temperature, and electricfield effects on the phase transition and piezoelectric responses of $\mathrm{K}_{0.5} \mathrm{Na}_{0.5} \mathrm{NbO}_{3}$ thin films. J. Appl. Phys. 123, 154106 (2018).

Open Access This article is licensed under a Creative Commons Attribution 4.0 International License, which permits use, sharing, adaptation, distribution and reproduction in any medium or format, as long as you give appropriate credit to the original author(s) and the source, provide a link to the Creative Commons license, and indicate if changes were made. The images or other third party material in this article are included in the article's Creative Commons license, unless indicated otherwise in a credit line to the material. If material is not included in the article's Creative Commons license and your intended use is not permitted by statutory regulation or exceeds the permitted use, you will need to obtain permission directly from the copyright holder. To view a copy of this license, visit http://creativecommons. org/licenses/by/4.0/.

(c) The Author(s) 2018 